\begin{tabular}{|l|l|}
\hline JURNAL ABDI MASYA & $\begin{array}{l}\text { Volume 1 Nomor } 3 \\
\text { November 2021 } \\
\text { pp 143-148 } \\
\text { Website: https://jurnal.sttw.ac.id/index.php/abma/about }\end{array}$ \\
\hline E-ISSN : 2774-2849 & P-ISSN : 2774-2881
\end{tabular}

\title{
PELATIHAN CNC MILLING RICHON GSK 218 MC DI SMK N4 SUKOHARJO
}

\section{RICHON GSK 218 MC CNC MILLING TRAINING AT SMK N4 SUKOHARJO}

\author{
Burhanudin $^{1 *}$, Ign.Henry Adi Nagoro², Heru Susanto ${ }^{3}$, Oppie $^{4}$ \\ 1,2,3,4 Program Studi Teknik Mesin, Sekolah Tinggi Teknologi Warga, Surakarta, Indonesia \\ *Email: burhanudin@sttw.ac.id
}

\begin{abstract}
ABSTRAK
Penguasaan kompetensi pengoperasian dan pemograman CNC Milling bagi Guru-guru Teknik Pemesinan di SMK N4 Sukoharjo adalah syarat untuk bisa menjelaskan penguasaan CNC kepada peserta didik. Keterbatasan akses penguasaan kompetensi dan pemograman CNC Milling Guruguru Pemesinan di SMK N4 Sukoharjo dikarenakan kurangnya sumber informasi yang kompeten menyebabkan Guru-guru Pemesinan di SMK N4 Sukoharjo banyak yang memiliki kompetensi tentang CNC yang masih sangat terbatas. Maka dari itu untuk meningkatkan kompetensi pengoperasian dan pemograman CNC Milling bagi Guru-guru Teknik Pemesinan di SMK N4 Sukoharjo diperlukan hadirnya sumber informasi yang benar-benar menguasai pengoperasian dan pemograman CNC untuk bisa digunakan sebagai sumber belajar. Dalam hal ini bentuk kegiatan yang bisa direalisasikan adalah Pelatihan Peningkatan Kompetensi Pengoperasian dan Pemograman CNC untuk Guru Pemesian di SMK N4 Sukoharjo yang dikemas dalam bentuk Pelatihan.. Kegiatan Pelatihan ini telah terlaksana selama dua hari di Laboratorium CNC SMK N4 Sukoharjo yang diikuti oleh Guru dan Toolmant SMK N4 Sukoharjo. Hasil dari pelatihan ini diperoleh $20 \%$ peserta pelatihan menjadi sangat menguasai dan sebanyak $50 \%$ dari peserta memiliki kompetensi menguasai pengoperasian dan pemograman CNC Milling.
\end{abstract}

Kata Kunci : pelatihan, pengoperasian, pemograman, CNC Milling, SMK N4 Sukoharjo

\section{Submit: 28 Oktober 2021 Accepted: 2 November 2021 Published: 26 November 2021}

\section{PENDAHULUAN}

SMK N4 Sukoharjo adalah salah satu sekolah SMK Negeri di Sukoharjo yang memiliki rumpun Teknik Pemesinan. SMK N4 Sukoharjo mendapatkan bantuan CNC Milling dari pemerintah pada akhir tahun 2020. Dari guru dan tenaga pendidik yang ada belum ada yang expert dalam penguasaan CNC terutama CNC Milling. Sedangkan tuntutan penguasaan pengoperasian dan pemograman $\mathrm{CNC}$ setelah bantuan $\mathrm{CNC}$ Milling turun merupakan kebutuhan yang urgent untuk bisa menggunakan dan merawat dengan pengetahuan yang cukup berkaitan dengan pengoperasiannya.

Disamping itu penguasaan pemograman dan pengoperasian CNC bagi lulusan rumpun Teknik Pemesinan merupakan sebuah tuntutan dalam industry Manufaktur sekarang ini. Hal ini dikarenakan hamper disetiap lini industry Manufaktur sudah berjalan menggunakan system otomasi dan CNC merupakan salah satu alat yang cukup vital untuk menunjang produksi disetiap lini industry Manufaktur. Maka dari itu penguasaan pemograman dan pengoperasian CNC oleh Guru-guru dan tenaga pendidik khususnya toolman untuk menunjang luaran lulusan yang kompeten dalam penguasaan $\mathrm{CNC}$ harus di kuasai dengan baik.

Rumusan masalah pada program pengabdian Masyarakat ini adalah; (1) Bagaimana methode pelatihan yang tepat untuk diterapkan dengan Batasan fasilitas dan waktu yanga ada, (2) Bagaimana meningkatkan kemampuan pengoperasian dan pemograman Guru-guru Teknik Pemesinan di SMK N4 Sukoharjo. Sehingga diperoleh methode yang tepat serta meningkatnya kemampuan pengoperasian dan pemograman Guru-guru Teknik Pemesinan di SMK N4 Sukoharjo. 
Manfaat yang diperoleh dari kegiatan ini antara lain (1) Tenaga pendidik di SMK N4 Sukoharjo khususnya rumpun Teknik Pemesinan akan lebih terampil dalam pengoperasian dan pemograman CNC Milling, (2) Guru Teknik Pemesinan di SMK N4 Sukoharjo akan lebih percaya diri dalam menyampaikan pemograman dan pengoperasian CNC Milling, (2) Meningkatkan kompetensi lulusan SMK N4 Sukoharjo terutama dalam bidang penguasaan CNC.

Menurut Schermerhorn (2011) [1] pelatihan merupakan serangkaian aktifitas yang bertujuan untuk memberikan kesempatan dan meningkatkan keterampilan berkaitan dengan pekerjaan. Sedangkan untuk mengukur hasil sebuah pelatihan diperlukan Langkah evaluasi. Tes merupakan salah satu jenis Langkah evaluasi yang digunakan untuk mengukur besarnya kemampuan seseorang secara tidak langsung, melalui respon seseorang terhadap stimulus atau pertanyaan [2].

Mesin $C N C$ adalah suatu mesin yang dikontrol komputer dengan menggunakan bahasa numeric (data perintah dengan kode angka, huruf, dan simbol) sesuai standart ISO. Sistem kerja teknologi $C N C$ ini akan lebih sinkron antara komputer dan mekanik, sehingga bila dibandingkan dengan mesin perkakas yang sejenis, maka mesin perkakas $C N C$ lebih teliti, lebih tepat, lebih fleksibel dan cocok untuk produksi massal. Dengan dirancangnya mesin perkakas $C N C$ dapat menunjang produksi yang membutuhkan tingkat kerumitan yang tinggi dan dapat mengurangi campur tangan operator selama mesin beroperasi [3].

Numeric Control $(N C)$ adalah suatu kendali mesin atas dasar informasi digital, ini diperkenalkan di area pabrikasi. $N C$ adalah bermanfaat untuk produksi rendah dan medium yang menvariasikan produksi item, dimana bentuk, dimensi, rute proses dan pengerjaan dengan mesin bervariasi. Mesin perkakas $N C$ meliputi mesin dengan operasi tujuan tunggal, yang memberikan informasi kuantitatif seperti pengerjaan dengan mesin operasi yang disajikan oleh suatu komputer kendali dengan program database yang menyimpan instruksi secara langsung untuk mengendalikan alat-alat bermesin $\mathrm{CNC}$ (Computer Numerically Control) [4].

\section{METODE}

Metode pelaksanaan kegiatan ini dilakukan dengan model pelatihan yang dilaksanakan selama dua hari di Laboratorium CNC SMK N4 Sukoharjo dengan melibatkan dua Mahasiswa STT Warga Surakarta. Untuk memecahkan masalah dalam kegiatan pengabdian ini team pengabdi membuat Langkah-langkah yang diperhitungkan dapat menyelesaikan masalah yang dihadapi. Untuk menarik perhatian peserta pelatihan materi yang disampaikan berupa pengenalan fisik mesin CNC Milling secara umum, baik nama-nama tiap bagian $\mathrm{CNC}$ beserta fungsinya, serta memperagakan langkah-langkah pengoperasian mesin CNC Milling secara sekilas. Tujuan dari tahapan awal ini adalah untuk menumbuhkan atensi dan motivasi dari peserta untuk mengikuti kegiatan secara menyeluruh dengan baik. 


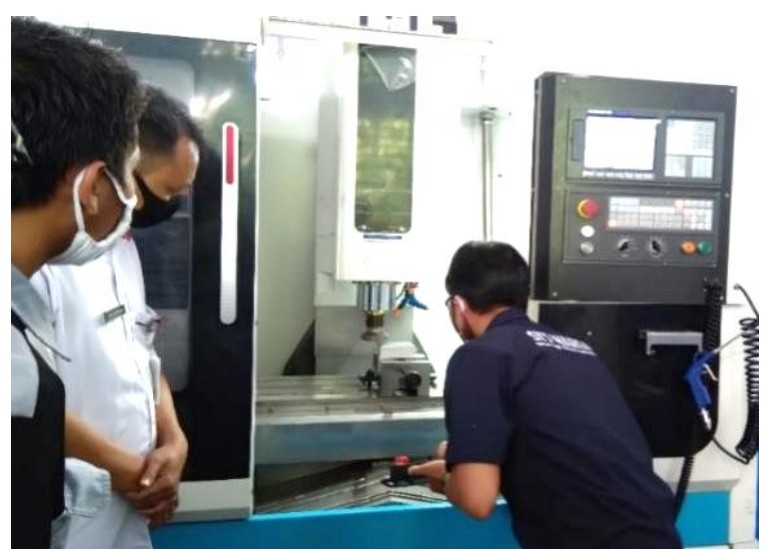

Gambar 1. Peragaan Pengoperasian Mesin CNC di awal Pelatihan

Langkah selanjutnya setelah dapat menarik perhatian dan memotivasi peserta pelatihan adalah dengan menyampaikan materi secara bertahap, yang dijelaskan melalui media white board dan didukung penjelasan pada mesin secara langsung. Tujuan dari methode ini digunakan sebagai variasi pelatihan juga digunakan agar peserta pelatihan paham secara langsung aplikasi pada mesin.

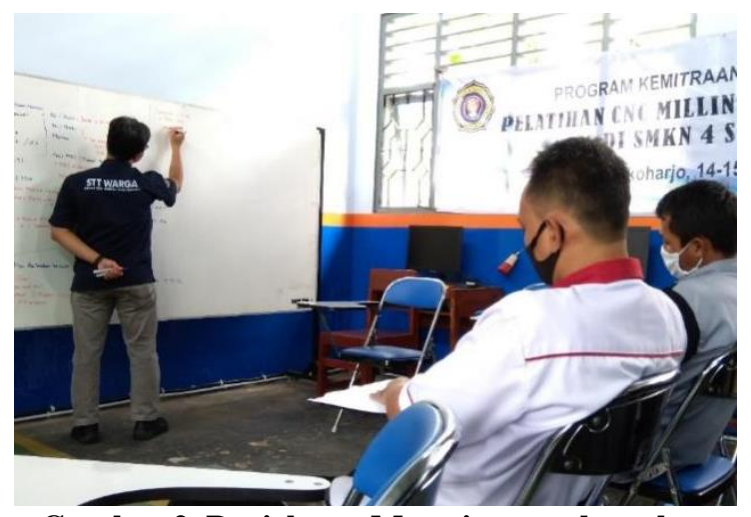

Gambar 2. Penjelasan Materi secara bertahap

Secara rinci metode pelaksanaan kegiatan ini bisa dilihat pada Tabel.1 dibawah ini;

Tabel 1. Rincian Kegiatan dan Metode Pelaksanaan

\begin{tabular}{|c|c|c|}
\hline No & Kegiatan & Metode \\
\hline 1 & $\begin{array}{l}\text { Pre Test kompetensi awal peserta berkenaan dengan } \\
\text { kemampuan pengoperasian dan pemograman CNC } \\
\text { Milling }\end{array}$ & Tes Individu \\
\hline 2 & $\begin{array}{l}\text { Observasi mesin, pengenalan bagian-bagian mesin } \\
\text { dan fungsinya }\end{array}$ & Ceramah, dan diskusi \\
\hline 3 & $\begin{array}{l}\text { Peragaan alur proses pengoperasian mesin dari turn } \\
\text { On mesin sampai eksekusi mesin }\end{array}$ & Unjuk Kerja \\
\hline 4 & $\begin{array}{l}\text { Penjelasan dan Peragaan Pengoperasian mesin CNC } \\
\text { Milling }\end{array}$ & $\begin{array}{l}\text { Ceramah, diskusi, unjuk } \\
\text { kerja }\end{array}$ \\
\hline 5 & Penjelasan pemograman CNC Milling & Ceramah dan diskusi \\
\hline 6 & $\begin{array}{l}\text { Penjelasan dan peragaan transfer program dan } \\
\text { simulasi program pada mesin CNC Milling }\end{array}$ & $\begin{array}{l}\text { Ceramah, diskusi, unjuk } \\
\text { kerja }\end{array}$ \\
\hline 7 & $\begin{array}{l}\text { Pemberian soal dan pembahasan program } \mathrm{CNC} \\
\text { Milling }\end{array}$ & Penugasan \\
\hline 8 & $\begin{array}{l}\text { Praktek Bersama dari setting hingga eksekusi } \\
\text { program }\end{array}$ & Praktek dengan pengawasan \\
\hline 9 & $\begin{array}{l}\text { Tugas mandiri baik program hingga eksekusi pada } \\
\text { mesin }\end{array}$ & Tugas dengan pengasawan \\
\hline 10 & Evaluasi dan post Test & Test Individu \\
\hline
\end{tabular}




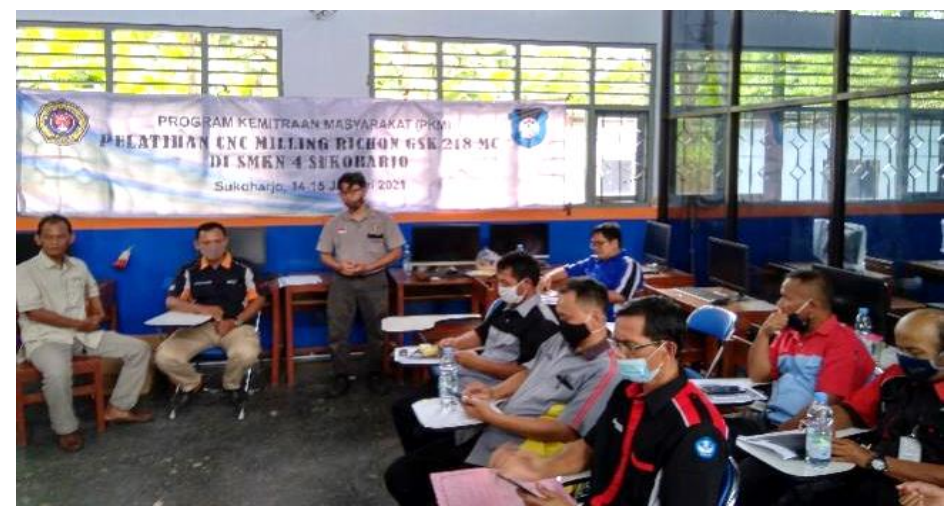

Gambar 3. Evaluasi Kegiatan

Materi pengoperasian CNC Milling yang disampaikan pada kegiatan ini antara lain:

1. Pengenalan fungsi dari tiap bagian-bagian mesin

2. Alat pendukung yang dibutuhkan dalam pengoperasian CNC Milling

3. Urutan menyalakan dan mematikan mesin

4. Penjelasan navigasi control CNC GSK

5. Setting benda kerja (sumbu $X$ dan $Y$ )

6. Setting alat potong (sumbu Z)

7. Input NC Program

8. Transfer NC Program

9. Simulasi NC Program

10. Eksekusi Program

Materi pemograman CNC yang yang disamapaikan, meliputi:

1. Data Teknologi pemograman $\mathrm{CNC}$

2. Data Geometri pemograman $\mathrm{CNC}$, meliputi;

3. G0 (gerak rapid)

4. G1 (gerak lurus dengan pengaturan feeding)

5. G2 (interpolasi radius searah jarum jam)

6. G3 (interpolasi radius berlawanan arah jarum jam)

7. G40 (kompensasi alat potong OFF)

8. G41 (kompensasi alat potong LEFT)

9. G42 (kompensasi alat potong RIGHT)

10. G83 (Siklus Peck Drill)

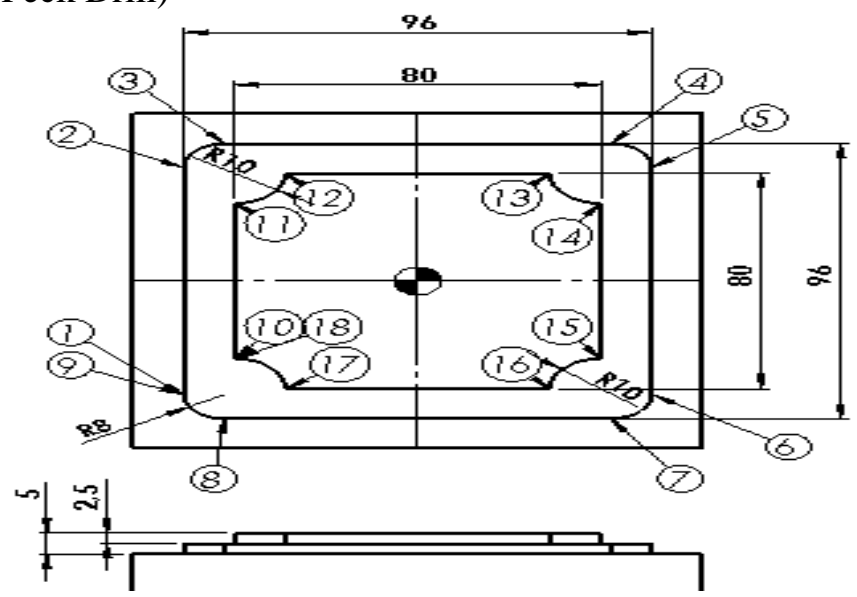

Gambar 4. Job Latihan Pemograman Aplikasi G41/G42 
Jawaban serta pembahasan Job Latihan pemograman

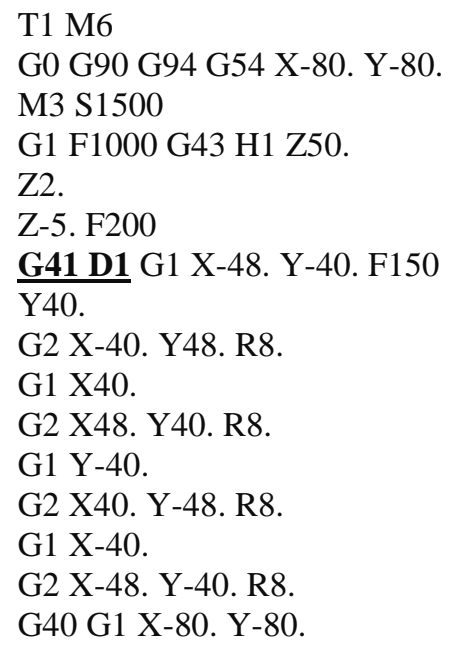

G41 D1 G1 X-40. Y-30.

G1 Y30.

G3 X-30. Y40. R10.

G1 X30.

G3 X40. Y30. R10.

G1 Y-30.

G3 X30. Y-40. R10.

G1 X-30.

G3 X-40. Y-30. R10.

G40 G1 X-70. Y-70.

G0 Z30.

G28 G91 Z0

G28 G91 X0 Y0

M5

M30

\section{HASIL DAN PEMBAHASAN}

Hasil dari kegiatan PkM Peningkatan Kompetensi Pengoperasian dan Pemograman CNC Milling untuk Guru-guru Pemesinan di SMK N4 Sukoharjo, menunjukkan peningkatan kompetensi yang cukup signifikan ditujukan dari hasil pree test dan post test yang telah dilakukan. Data peningkatan kompetensi tersebut ditujukkan pada Gambar 3. sebagai berikut.

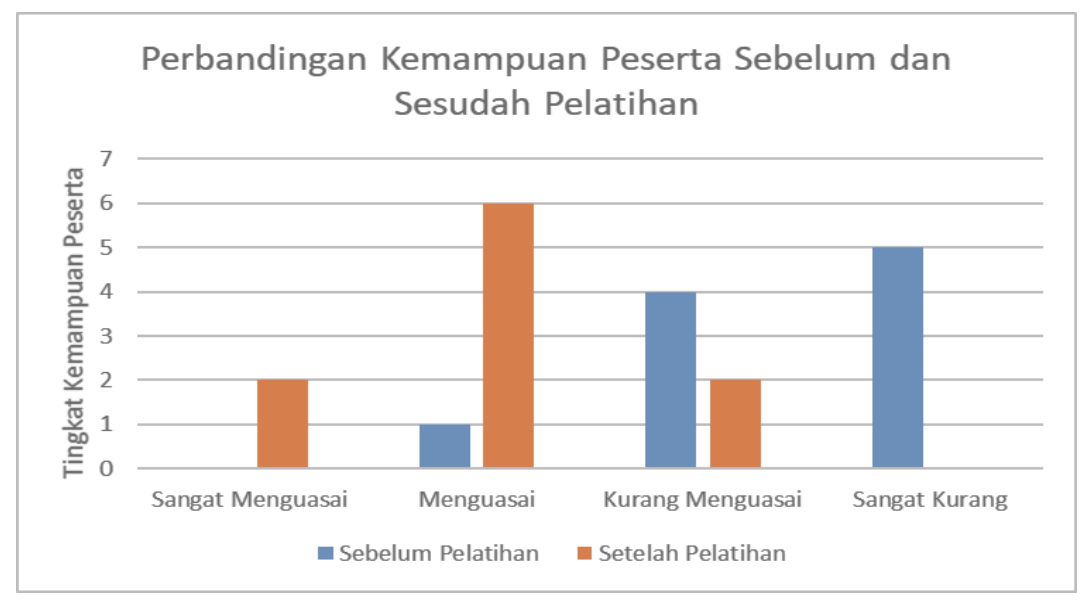

Gambar 5. Perbandingan Kemampuan Peserta Sebelum dan Sesudah Pelatihan

Dari data awal kegiatan dapat kita ketahui bahwa 50\% peserta yang mengikuti pelatihan memiliki kompetensi yang sangat kurang dalam penguasaan CNC Milling, 40\% Kurang menguasai dan 10\% Menguasai. Peserta yang diawal memiliki kompetensi menguasai ini merupakan Guru CNC di SMK N4 Surakarta, sehingga dipastikan sudah memiliki bekal pengetahuan tentang CNC. Sedangkan yang lain merupakan guru-guru serta toolman rumpun pemesinan yang masih sangat awam dengan pengoperasian dan pemograman CNC.

Setelah pelaksanaan kegiatan diperoleh data bahwa ada 20\% peserta dengan kompetensi sangat menguasai $60 \%$ menguasai dan 20\% kurang menguasai. Disini kita bisa lihat peningkatan penguasaan kompetensi yang cukup signifikan. Presentase peningkatan jumlah peserta yang memiliki kompetensi "sangat menguasai" yang pada awal kegiatan tidak ditemukan atau $0 \%$ mengalami peningkatan 
sebesar $20 \%$, kompetensi "menguasai" mengalami peningkatan $50 \%$ dari sebelumnya yang hanya berkisar $10 \%$, akan tetapi masih ditemukan $20 \%$ peserta yang kurang menguasai.

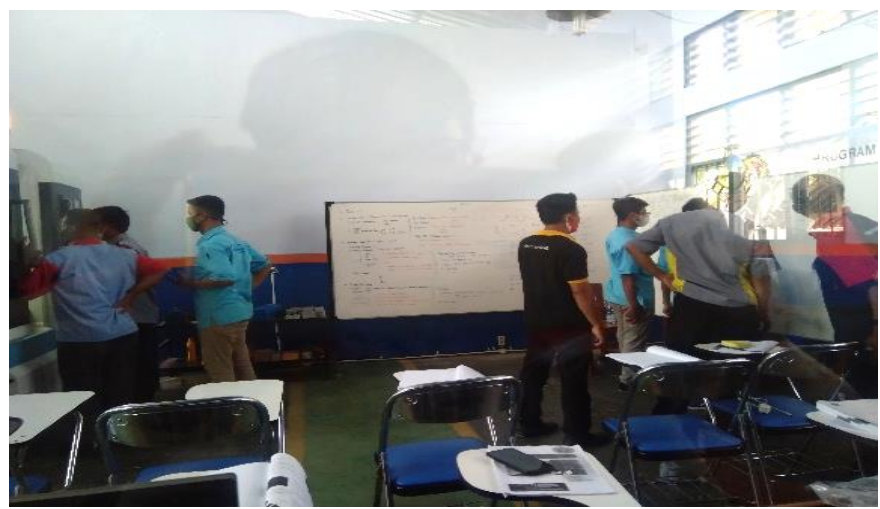

Gambar 6. Pelaksanaan tugas mandiri dan Praktek yang didampingi oleh Mahasiswa

Evaluasi pelaksanaan kegiatan ini dikarenakanmasih ada $20 \%$ peserta yang masuk katagori kurang menguasai dikarenakan basic skill peserta, waktu dan fasilitas kegiatan. Basic skill peserta yang beragam menyebabkan pada saat materi disampaikan memiliki kemungkinan pemahaman beserta tidak sesuai yang diharapkan oleh instruktur kegiatan. Hal ini ditambah waktu yang kurang Panjang untuk mengakomodasi semua peserta melakukan praktek dengan durasi waktu yang sama, serta fasilitas praktek yang hanya dengan satu mesin, sehingga menyebabkan peserta ada yang tidak berkesempatan melakukan praktek secara langsung dengan waktu yang cukup.

Solusi permasalahan ini bisa diatasi dengan pelaksanaan yang direncanakan dengan durasi lebih dari dua hari dengan penambahan fasilitas pendukung praktek yang memadai.

\section{KESIMPULAN}

Kegitan Peningkatan Kompetensi Pengoperasian dan Pemograman CNC Milling untuk Guruguru Pemesinan di SMK N4 Sukoharjo, yang diwujudkan dalam bentuk pelatihan dapat meningkatkan kompetensi pengoperasian dan pemograman CNC Milling sebesar 20\% peserta sangat menguasai, 50\% menguasai. Hal ini bisa disimpulkan bahwa kegiatan ini bisa meningkatkan kompetensi Guru-guru Teknik Mesin di SMK N4 Sukoharjo secara signifikan. Kekurangan pada kegiatan ini bisa diatasi dengan menambah waktu pelatihan serta sarana dan prasarana pelatihan yang mendukung sehingga peserta pelatihan mendapatkan waktu yang cukup untuk menerima semua materi dan mendapatkan kesempatan yang sama dalam penggunaan alat-alat pelatihan yang digunakan.

\section{UCAPAN TERIMA KASIH}

Ucapan terimakasih kami sampaikan kepada seluruh pejabat serta guru-guru SMK N4 Sukoharjo yang mengizinkan penggunaan alat serta waktu juga sambutan yang luar biasa pada pelaksana kegiatan ini.

\section{DAFTAR PUSTAKA}

[1] J. Schermerhorn, Introduction to Management, John Wiley \& Son, 2011.

[2] Djemari. M, "Pengukuran, Penilaian dan Evaluasi," PPPG, Yogyakarta, 1999.

[3] W. Sumbodo, Teknik Mesin Industri jilid 1, 2, 3, Jakarta: Depdiknas, 2008.

[4] W. Sumbodo, CAD CAM CAE. Buku Ajar Mata Kuliah CNC, Semarang: UNNES, 2011. 